\title{
Investigation of geotechnical, hydromechanical, and chemical behaviour of polymer-treated tailings
}

\author{
M Boshrouyeh Ghandashtani Sustainable Minerals Institute, The University of Queensland, Australia \\ M Edraki Sustainable Minerals Institute, The University of Queensland, Australia \\ A Costine CSIRO Mineral Resources, Australia \\ T Baumgartl Geotechnical and Hydrogeological Engineering Research Group, Federation University, \\ Australia
}

\begin{abstract}
This study investigated the properties of flocculated materials formed in a laboratory-scale inline flocculation setup at a high solid concentration of artificial tailings. Water scarcity and the willingness of using seawater in mineral processing where access to fresh water is limited highlights the importance of understanding the salinity effects on the tailings treatment processes. To better understand the inline flocculation technique for enhanced water recovery from fine-particle suspensions, this paper studied the impacts of two typical salts, $\mathrm{NaCl}$ and $\mathrm{CaCl}_{2}$ on the geotechnical, hydrological, hydromechanical, and chemical behaviour of polymer-treated synthetic tailings slurry using a low-shear mixer for continuous flocculation under controlled conditions. A standard consolidation test was used to investigate the differences in geotechnical properties and functions between the raw and polymer-treated tailings in presence of added salt. Increasing the calcium concentration was more adversely impacted by the low molecular weight (MW) copolymers in producing aggregates with lower water recovery and turbidity and gave the greatest zeta potential compared to other polymer chemistry.

Among the polyacrylamide/polyacrylate copolymers, Magnafloc ${ }^{\circledR} 5250$ flocculant responded more effectively at the low $\mathrm{CaCl}_{2}$ salinity by producing higher zeta potential and fast realising of the less turbid water compared to that of $\mathrm{NaCl}$. Greater compatibility between the high $\mathrm{NaCl}$ salinity with the high $\mathrm{MW}$ copolymer was also exhibited in terms of facilitating the polymer chains activities to create stronger aggregates. The saturated hydraulic conductivity of samples was evaluated, and the pore size distribution was analysed by determination of the water retention characteristics of the materials. Results indicated a significant difference in geotechnical and hydrological properties between the untreated and polymer-treated slurries, including: (i) a higher void ratio for the polymer-treated samples containing $\mathrm{CaCl}_{2}$; (ii) different patterns of settlement under the applied vertical stress during consolidation of the specimens; and (iii) $40 \%$ more free water drainage from samples salted with $\mathrm{CaCl}_{2}$ and treated by adding polymer. The results are discussed in light of the contribution of the polymer treatment to improved rehabilitation outcomes and the role geotechnical, hydromechanical, hydrological and chemical properties play to achieve this goal.
\end{abstract}

Keywords: inline flocculation, dewatering rate, consolidation, aggregates microstructure, water recovery, salinity

\section{Introduction}

Inline flocculation involves the injection of concentrated polymer solutions into a tailings pipeline at or close to the point of discharge depending on the prevailing mixing conditions and the site-specific requirements on deposition (e.g. water recovery or steepened beach development) (Reid et al. 2009; Torres Lopez et al. 2019). The addition of high dosages of polymer to high solids tailings streams leads in some way to an effective densification of the aggregate structures with further dewatering achieved compared to traditional techniques (Sabah \& Cengiz 2004). Given the high dosages being applied in line, there is considerable scope 
for optimisation particularly if the properties of the treated tailings can be tailored for more favourable rehabilitation or mine closure outcomes. However, the effect of operating parameters and liquor chemistry on high solids flocculation is at present poorly understood, such that industrial applications are often considered trial-and-error processes. Among the parameters that can influence the final properties of polymer-treated tailings, the ionic strength of the liquor, polymer chemistry and applied shear are known to affect the size and structure of aggregates formed (Du et al. 2010; Jeeravipoolvarn 2010; Tombácz \& Szekeres 2004; Wells et al. 2011).

A better understanding of the underlying processes involved in inline flocculation at high polymer dosages provides an opportunity for improved management, design, and rehabilitation of mine tailings in a more sustainable manner. In this regard, considering the soluble salts in mine tailings that could be added during the mineral processing (using seawater or hypersaline liquors due to less access to the fresh water) is one of the factors that can change the distribution of tailings slurry particles via coagulation of suspension and affect the performance of flocculation process later by adding polymers (Costine et al. 2014; Watson et al. 2011).

On the other hand, the addition of high dosages of polymer to high solids tailings streams leads in some way to an effective densification of the aggregate structures with further dewatering achieved compared to traditional techniques (Pinheiro et al. 2012). Although, by implementing this method, tailings can appear on deposition point with rapid water releasing, there is still required a comprehensive study to understand the geotechnical properties of this material as critical factors to be investigated for the flow behaviour of tailings plus design and construction of the tailings dams (Yu 2015). Moreover, hydraulic factors, such as saturated hydraulic conductivity, porewater pressure, water retention capacity and suction development due to desiccation, control the hydraulic performance of polymer-treated tailings, which also has significant influence on its mechanical stability, durability and environmental performance (Ghirian \& Fall 2013; Jcu 2004).

Using the inline flocculation technique for the high solid/high polymer dosage systems appears to have some gaps in knowledge including the simultaneous impacts of salinity and type of the polymer, and assessing their effects on the physical and chemical properties of produced aggregates. Hence, the initial objective of this study was to analyse the effect of different types of polymers in the presence of monovalent and divalent salts on the inline flocculation of artificial tailings. There are also some questions regarding the capability of this method for producing stable aggregates from the geotechnical and hydromechanical point of view. Therefore, the second focus of this study was to evaluate the impact of polymer addition technique on different geotechnical properties such as settling rate, consolidated density, solid concentration, rate of consolidation, and hydraulic conductivity.

\section{Experimental}

\subsection{Materials}

Kaolinite-NY prestige, silica 200G, and silica fine sand were purchased from Sibelco, Australia. The names and general descriptions of the flocculants used in this study are given in Table 1, along with the codes used to identify them in the subsequent discussion. All were powder products obtained from BASF. The acrylamide/acrylate copolymer flocculants were Magnafloc ${ }^{\circledR} 156$, Magnafloc ${ }^{\circledR} 336$, and Magnafloc ${ }^{\circledR} 5250$; the latter having a highly branched structure (unique molecular architecture) (ed. Williams 2007). Magnafloc $^{\circledast} 156$, Magnafloc ${ }^{\circledast}$ 5250, and Magnafloc $^{\circledR} 336$ have the intrinsic viscosity (IV) of 12,18 and $24 \mathrm{dL}$ g-1, respectively [20] and these amounts were used to code each flocculant in form of IV12, IV18 and IV24, correspondingly. $\mathrm{NaCl}$ and $\mathrm{CaCl}_{2}$ were used to alter the salinity of the artificial tailings. Distilled water was used for both the slurry make-up and polymer solution preparation in all experiments. 
Table 1 Turbidity of drainage water collected from $\mathrm{NaCl}$ and $\mathrm{CaCl}_{2}$ slurries with three different polymers

\begin{tabular}{|c|c|c|c|c|}
\hline Test & Polymer & Salt/concentration & Turbidity (NTU) & Zeta potential (mV) \\
\hline 1 & Magnafloc $^{\circledR} 156$ (IV12) & $\mathrm{NaCl} / 0.006 \mathrm{M}$ & 547 & -16.5 \\
\hline 2 & Magnafloc ${ }^{\circledR} 156$ (IV12) & $\mathrm{NaCl} / 0.6 \mathrm{M}$ & 80.8 & 2.6 \\
\hline 3 & Magnafloc $^{\circledR} 5250$ (IV18) & $\mathrm{NaCl} / 0.006 \mathrm{M}$ & 575 & -15 \\
\hline 4 & Magnafloc ${ }^{\circledR} 5250$ (IV18) & $\mathrm{NaCl} / 0.6 \mathrm{M}$ & 58.5 & 1.8 \\
\hline 5 & Magnafloc ${ }^{\circledR} 336$ (IV24) & $\mathrm{NaCl} / 0.006 \mathrm{M}$ & 316 & -16.5 \\
\hline 6 & Magnafloc ${ }^{\circledR} 336$ (IV24) & $\mathrm{NaCl} / 0.6 \mathrm{M}$ & 76.9 & 7.4 \\
\hline 7 & Magnafloc $^{\circledR} 156$ (IV12) & $\mathrm{CaCl}_{2} / 0.006 \mathrm{M}$ & 37.7 & -7.2 \\
\hline 8 & Magnafloc ${ }^{\circledR} 156$ (IV12) & $\mathrm{CaCl}_{2} / 0.06 \mathrm{M}$ & 111.7 & -4.9 \\
\hline 9 & Magnafloc $^{\circledR} 5250$ (IV18) & $\mathrm{CaCl}_{2} / 0.006 \mathrm{M}$ & 68.1 & -2.9 \\
\hline 10 & Magnafloc $^{\circledR} 5250$ (IV18) & $\mathrm{CaCl}_{2} / 0.06 \mathrm{M}$ & 49.2 & -8.5 \\
\hline 11 & Magnafloc ${ }^{\circledR} 336$ (IV24) & $\mathrm{CaCl}_{2} / 0.006 \mathrm{M}$ & 73.7 & -2.3 \\
\hline 12 & Magnafloc ${ }^{\circledR} 336$ (IV24) & $\mathrm{CaCl}_{2} / 0.06 \mathrm{M}$ & 50.1 & -10.2 \\
\hline
\end{tabular}

\subsection{Slurry and polymer preparation}

A synthetic homogenous slurry was used in all experiments to avoid the natural variability that exists with real tailings samples and to enable the preparation of large batches for testing. A slurry was prepared at $50 \mathrm{wt} \%$ from a combination of $25 \%$ kaolin, $45 \%$ silica $200 \mathrm{G}$ (93\% finer than $53 \mu \mathrm{m}$ ), and $30 \%$ silica fine sand ( $99 \%$ finer than $0.3 \mathrm{~mm}$ ), as described elsewhere (Reid \& Fourie 2016). The specific gravity of the slurry was 2.64. Conditioning of the slurries was done at $1,200 \mathrm{rpm}$ for five days in a baffled $200 \mathrm{~L}$ tank to ensure a stable, reproducible size for the duration of testing. All polymer solutions were prepared at $0.4 \mathrm{wt} \%$ concentration with the same salt concentration as its associated slurry. The weighed polymer was added slowly to the vortex produced in salted water under vigorous mixing to fully disperse the powder. Initial strong agitation with an $\mathrm{A} 310$ impeller at $250 \mathrm{rpm}$ for 30 minutes was followed by gentle agitation (80-100 rpm) for $16 \mathrm{~h}$ to produce clear, homogenous solutions. Flocculant solutions were aged for three days in a cool room $\left(4^{\circ} \mathrm{C}\right)$ to ensure they were optimally active before adding to the slurry.

\subsection{Experimental design}

To study the impacts of salt, a low and high concentration of $\mathrm{NaCl}$ and $\mathrm{CaCl}_{2}$ were studied for each polymer. For each salt, a low concentration of $0.006 \mathrm{M}$ and a high concentration of $0.6 \mathrm{M}$ and $0.06 \mathrm{M}$ were chosen for $\mathrm{NaCl}$ and $\mathrm{CaCl}_{2}$, respectively, covering the typical concentration ranges encountered in plants using seawater or hypersaline liquors. In the case of $\mathrm{CaCl}_{2}$, concentrations above $0.06 \mathrm{M}$ resulted in the precipitation of flocculants (Ramos et al. 2020). The polymer dosage, expressed as grams of polymer per tonne of dry solids, was kept constant at $1,000 \mathrm{~g} / \mathrm{t}$ (gram of polymer powder per tonne of dry tailings), which was previously shown to give effective flocculation of similar slurries across a range of polymer molecular weights without the risk of overdosing (Costine et al. 2018a).

\subsection{Inline polymer addition}

An established lab-scale experimental setup was used to simulate the inline flocculation process in this research (Costine et al. 2020). The experimental setup was developed for assessing polymer performance in high solids tailings applications because conventional testing with using beakers, plungers, and mechanical devices can lead to compromised performance that is more reflective of the applied mixing conditions than the polymers themselves. The main advantage of the low-shear chaotic mixer (or topological mixer) as a 
laboratory tool is that it gives a uniform shear history across the vessel, in contrast to the distinct zones of shear that will exist in a stirred tank. Continuous tests in the chaotic mixer have shown that flocculated solids are less sensitive to over-shearing due to the gentle braiding motion of the rotating rods, which offers scope to properly identify polymer properties that are best suited to the process (Fawell et al. 2015). To control the polymer dosage, polymer solution $(45 \mathrm{~mL} / \mathrm{min})$ and slurry $(0.25 \mathrm{~L} / \mathrm{min})$ were pumped to the inlet of the preconditioning coil ( $1 \mathrm{~m}$ length, $7.7 \mathrm{~mm}$ ID) before entering the chaotic mixer for mild mixing, and the final products collected from the discharge point.

\subsection{Water recovery and supernatant quality}

For each condition studied, a sample of flocculated solids was collected and placed on an elevated $4^{\circ}$ slope table with deposition cells. The polymer-treated solids were sufficiently thick to form a beach at the top of the deposition cell, allowing released water to pass freely through membrane-covered drainage holes for collection and data logging using WinCT Ver. 5.40 (Windows Communication Tools) which is a program for transmitting data from an A\&D balance to a computer. Cells were covered for the duration of the test to minimise evaporative losses. The net water recovery was calculated as the amount of water collected by gravity drainage after $24 \mathrm{~h}$ relative to the amount of water added in the feed slurry and polymer solution, expressed as a percentage. The $\mathrm{pH}$ of the released water was measured using a HACH Semsion+ $156 \mathrm{MM}$ multimeter ( $\mathrm{HACH}$, Australia) and its clarity recorded by a WP81 turbidity meter (TPS Pty Ltd, Australia) measured in units of NTU.

\subsection{Zeta potential}

A Zeta Probe instrument (M/s Colloidal Dynamics Ltd, USA) was used for measuring the zeta potential of the flocculated solids. This measurement was carried out by preparing a $5 \mathrm{wt} \%$ sample in a background solution of $0.001 \mathrm{M}$ salt (using the same salt as that used for slurry preparation). The agitation rate during the test was fixed on $180 \mathrm{rpm}$, and the final value was the average of five measurements.

\subsection{Cryo-SEM}

Morphological properties of the aggregated tailings were investigated using Cryo-SEM. An EM HPM 100 high-pressure freezer (HPF) technique was applied to prevent ice crystal formation or soluble aggregation that could provide poor/limited vitrification. Scanning electron microscopy (JEOL JSM 7001F FESEM) was operated at different voltages and magnifications to compare the treated and untreated tailings.

\subsection{Consolidation test}

Consolidation testing was performed using a standard oedometer with a cross-sectional area of $39.8 \mathrm{~cm}^{2}$. The initial specimen height was kept at $150 \mathrm{~mm}$. An approach combining initial constant rates of loading and step loading was employed on both samples. Seven loading rates of $0.1,0.2,0.4,0.8,1.6$, and $3.2 \mathrm{kPa} / \mathrm{min}$, and six loading steps of 20,40,80,160,320, 640 and 1,000 kPa were adopted to consolidate the samples. Each loading step was allowed to consolidate the specimen for a maximum period of $24 \mathrm{~h}$ or when the settling changes reached $0.01 \mathrm{~mm}$. After the establishment of each loading step, allocated time could consolidate the sample and to dissipate excess porewater pressure (Islam et al. 2020).

\subsection{Test to determine hydraulic properties}

To analyse the samples in terms of their soil physical properties, the water retention curve was determined by initially desiccating each sample on $-1,-2$ and $-3 \mathrm{kPa}$ for $24 \mathrm{~h}$ each using a sand-based tension table. To this end, both the untreated and treated samples were placed into a soil core sample holder ( $5.6 \mathrm{~cm}$ ID and $4 \mathrm{~cm}$ depth). To achieve lower suction points, a vacuum controlled pressure pump was applied on a porous plate where the cores were placed for four, six and five days, sequentially to achieve water content at $-10,-30$ and $-50 \mathrm{kPa}$. The latest step was desiccation at $-500 \mathrm{kPa}$ using a pressure plate extractor (1500F1; Soil Moisture, Santa Barbara, USA) for three weeks. After the final step, samples dried at $105^{\circ} \mathrm{C}$ for at least $24 \mathrm{~h}$ 
to calculate the bulk density (Shaygan et al. 2017; Yang \& You 2013). It should be mentioned that it was not possible to keep the raw tailings with $50 \mathrm{wt} \%$ water content in a sample holder, so the sample was left for $48 \mathrm{~h}$ in a bucket to settle, and then the sediment with the measured water content transferred to the soil core for running the test.

\section{$3 \quad$ Results and discussion}

\subsection{Impacts of salinity and flocculants chemistry}

Figure 1 shows the graph of water removal over the first $5 \mathrm{~h}$ that the most (>95\%) of the recoverable water by gravity drainage was collected. There was an impact on the quality and quantity of the drained water based on the water removal pattern over time. The fastest water recovery rate was recorded for the unique molecular architecture flocculant (IV18) at the $0.006 \mathrm{M}$ concentration of $\mathrm{NaCl}$, while at the higher $0.6 \mathrm{M} \mathrm{NaCl}$ concentration, the high molecular weight (MW) polyacrylamide/polyacrylate flocculant (IV24) led to the maximum water releasing compared to other polymers in this salt concentration. Like the low concentration of $\mathrm{NaCl}$ at the $0.006 \mathrm{M}$ of $\mathrm{CaCl}_{2}$, the IV18 polymer resulted in the fastest water recovery, but with a lower amount. High concentration of $\mathrm{CaCl}_{2}$ showed the slowest water recovery in general, with final values less than all other tested conditions. The pattern of water release can influence both the final amount and the clarity of the recovered water after polymer addition, which might be related to the produced network structure.
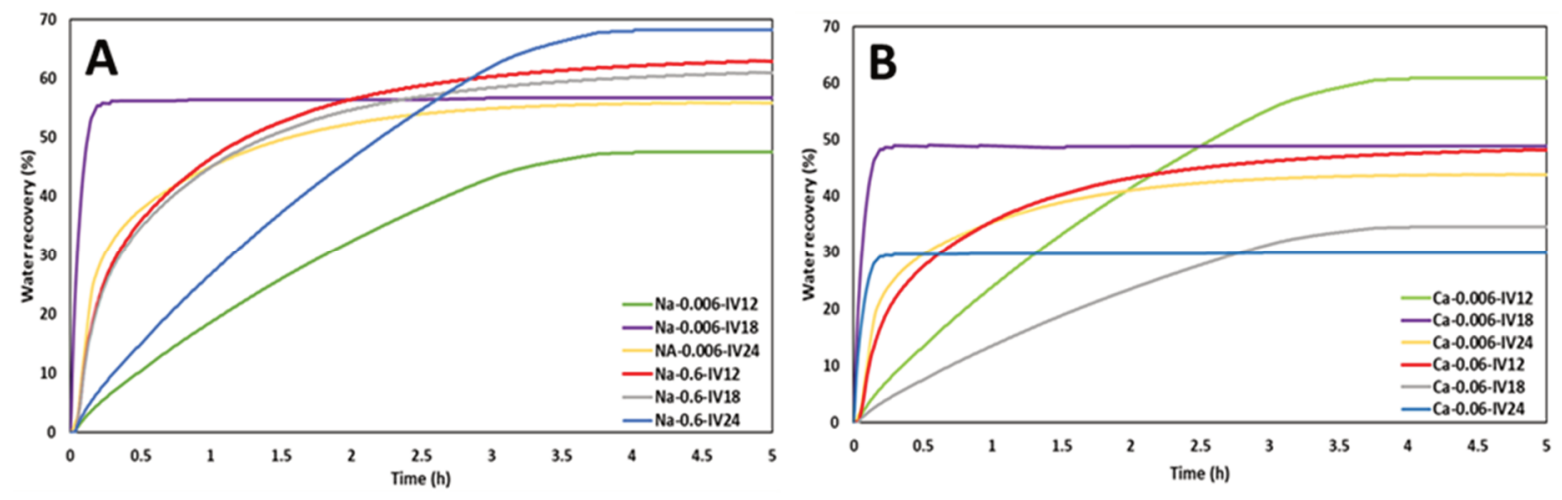

Figure 1 Water recovery curves for four different polymers in the presence of (a) $\mathrm{NaCl}$ (b) $\mathrm{CaCl}_{2}$

Along with the amount of runoff water collected, the quality of the water in terms of suspended solids is also important. To assess this, the turbidity of each sample was measured as shown in Table 1. Additionally, the strength of the flocculated solids created by adding different kinds of polymers was evaluated by measuring the zeta potential and presented in Table 1 as well. The most turbid released water was recorded for the flocculated samples at the lower concentration of $\mathrm{NaCl}$. Opposite to the $\mathrm{NaCl}$ samples, increasing the $\mathrm{CaCl}_{2}$ concentration was not influential in changing the released water turbidity substantially, except for the polyacrylamide/polyacrylate at the lowest MW (IV12) that recorded the highest water turbidity for the high $\mathrm{CaCl}_{2}$ concentration.

It is important to examine the impact of different types of flocculants on the salted tailings slurries through the flocculation process to reach rapid dewatering with low turbidity and high amount of recovered water. Among the $\mathrm{NaCl}$ samples, IV18 at the lower salinity conditions created a kind of aggregates with the potential of fast water release with high turbidity. On the other hand, this flocculant in presence of low $\mathrm{CaCl}_{2}$ concentration made a structure for the materials with slower water recovery rate and significantly greater clarity. Thus, the rate of water removal regardless of the quantity can control dispersing the suspended particles into the released water to affect the turbidity. However, this correlation between the rate of water removal and the quality of released water is less effective for the IV24 with higher MW in comparison between the $\mathrm{NaCl}$ and $\mathrm{CaCl}_{2}$ high concentrations. IV24 showed the fastest and less recovered water on high $\mathrm{CaCl}_{2}$ condition while the slowest and higher recovered water was recorded for it at the high $\mathrm{NaCl}$ salted 
slurry with the same turbidity. Here, the bridging mechanism of this high MW conventional polyacrylamide/polyacrylate is more dominant in controlling the water quality and trapping the fine particles within the aggregates. Differing from the $\mathrm{NaCl}$ cases that showed the highest water recovery in a high salt concentration, the highest amount of water recovered from the samples with $\mathrm{CaCl}_{2}$ recorded at the low concentration $(0.006 \mathrm{M})$ in presence of IV12 polymer. The turbidity of this sample was the lowest one among all the other $\mathrm{CaCl}_{2}$ cases with $37.7 \mathrm{NTU}$. Although the rate of dewatering in this case was not the slowest one based on the slope of the water recovery curve (Figure 1b), it released the clearest water after flocculation.

Moreover, the increase of $\mathrm{CaCl}_{2}$ only affected the water turbidity (a significant rise) in flocculation with IV12 compared to that of other polymers. Similar results were reported for the low solid systems applications in which increasing the $\mathrm{Ca}^{2+}$ concentration showed negative effect on the flocculation by decreasing the bridging capacity in lower MWs of conventional polyacrylamide (Costine et al. 2018b). On the other hand, among the salted samples with the high $\mathrm{CaCl}_{2}$ concentration, the IV12 polymer showed the highest water recovery. It also gives the impression that in high solid systems, even though the low MW polymers have fewer potential points of attachment per molecule, the probability of successful collisions due to concentrated particles stream is high and resulted in a higher water recovery. The presence of the $\mathrm{Ca}^{2+}$ ions in the slurry affected the mineral particles by adsorption of cations and changing the active sites for flocculants adsorption, and subsequently varying the flocculant conformation. In a study by Arinaitwe \& Pawlik (2013), it was demonstrated that a small amount of calcium $(0.001 \mathrm{~mol} / \mathrm{L})$ was sufficient to reduce the intrinsic viscosity to a value indicating a physical limit of coiling of the polymer chains and diminish the flocculation.

Regarding the zeta potential, increasing the $\mathrm{NaCl}$ concentration from $0.006 \mathrm{M}$ to $0.6 \mathrm{M}$ resulted in significant increase in the zeta potential values toward the higher positive amount that represented more double layer compression and stronger binding between aggregates. At the high $\mathrm{NaCl}$ concentration, the IV18 polymer that expected to be more interactive in making stronger aggregates could not make high degree flocculation and showed lower zeta potential compared to other flocculants. In terms of $\mathrm{Ca}^{2+}$ impact on the properties of created aggregates, a high $\mathrm{CaCl}_{2}$ concentration produced a low zeta potential (except for the IV12 which showed the more negative zeta potential) and confirmed the loose internal force between the aggregates, while according to the previous studies, at the higher salinity in this situation with less water release, the created aggregates are more compact with a weaker network structure.

Based on all above characterisation techniques and analyses of the 12 cases, one sample of each type of salt was selected to introduce the desirable condition to have the highly efficient inline flocculation process for high solid systems based on the involved factors, including the salt concentration and type of the polymer. For $\mathrm{NaCl}$ at higher concentration $(0.6 \mathrm{M})$ and in the presence of IV24 polymer, this slurry gave a network structure with a slow rate but high amount of water recovery which is the maximum achieved recovered water among all the experiments. The selected sample resulted in the maximum positive amount of the zeta potential as well, which is a strong indication of the inter-aggregates interaction forces. Similar criteria were applied for selecting the best $\mathrm{CaCl}_{2}$ salted sample. IV18 polymer produced the optimal aggregates in low $\mathrm{CaCl}_{2}$ salinity $(0.006 \mathrm{M})$ due to producing aggregates with around $50 \%$ water recovery. Using the IV18 polymer with its highly branched and interactive chains compared to the conventional flocculants results in aggregates with denser structure at low $\mathrm{CaCl}_{2}$ concentration. As shown in the previous studies, this type of flocculant produces flocculant solutions containing a proportion of semi-particulate entities and polymer chains attached in three dimensions which make stronger flocculated solids with less inter-aggregates water (Pearse 2003). Thus, this unique molecular architecture polymer has a greater activity and more efficient flocculation in the low $\mathrm{CaCl}_{2}$ salinity by having higher zeta potential and fast realising of the less turbid water, and based on the presented Cryo-SEM image on Figure 2a, particles connected in an accumulative structure compared to the untreated sample. 

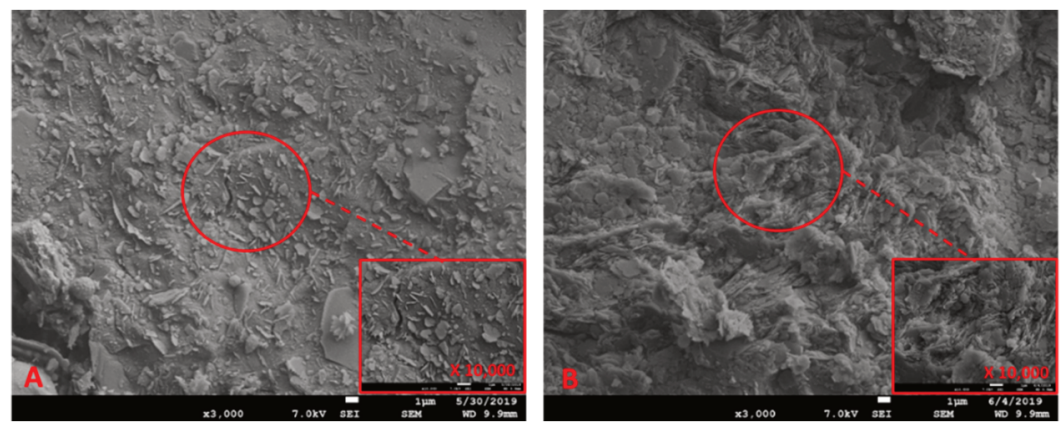

Figure 2 Cryo-SEM images for (a) Untreated slurry; (b) $\mathrm{CaCl}_{2}-0.006 \mathrm{M}$ with IV18

Therefore, it can be inferred that the structure and properties of created aggregates through the polymer addition are strongly dependent on the salinity of the initial tailings slurry and can be altered by increasing the salt concentration. Thus, awareness of the potential impacts of the saline liquor on the polymer activity, particularly at high solid slurry, facilitates more efficient operation of creating flocculated solids with enhanced dewatering rate and structure that can facilitate rehabilitation. In this regard, it is worth conducting further studies ion producing flocculated material in a reproducible manner for subsequent consolidation experiments to investigate the geotechnical and hydrological properties of created aggregates in high solid slurries. To this end, the low concentration of $\mathrm{CaCl}_{2}$ with the IV18 polymer was selected for the rest of experiments discussed below.

\subsection{Geotechnical parameters and hydromechanical behaviour}

Figure 3 shows the results of the settlement with the corresponding applied stress on both the untreated sample and a sample treated by polymer (IV18) at high concentration of $\mathrm{CaCl}_{2}$ in terms of the volume of settled sediments (in unit of $\mathrm{mm}$ ) and recorded applied stress from the top (in unit of $\mathrm{kPa}$ ). The initial moisture contents for the untreated tailings slurry and polymer amended sample were $71 \%$ and $51 \%$, respectively. As is clear from the graph, the time for reaching the stable condition after each loading step is different for raw slurry and polymer-treated samples. The speed and the value of settlement during the first two cycles is greater for the raw slurry by recording more than $8 \mathrm{~mm}$ changing in its height compared to that of a polymer-treated one with less than $2 \mathrm{~mm}$. Two initial faster rates of settling for the raw slurry caused the larger final settlement at the end of the test compared to the polymer-treated sample which already was thickened and lost most of its water content. Stable changes over different applied loads for the polymer-treated samples shows the impact of changing the texture of the materials by adding the polymer that could reach the stable condition and less variation under the stress.
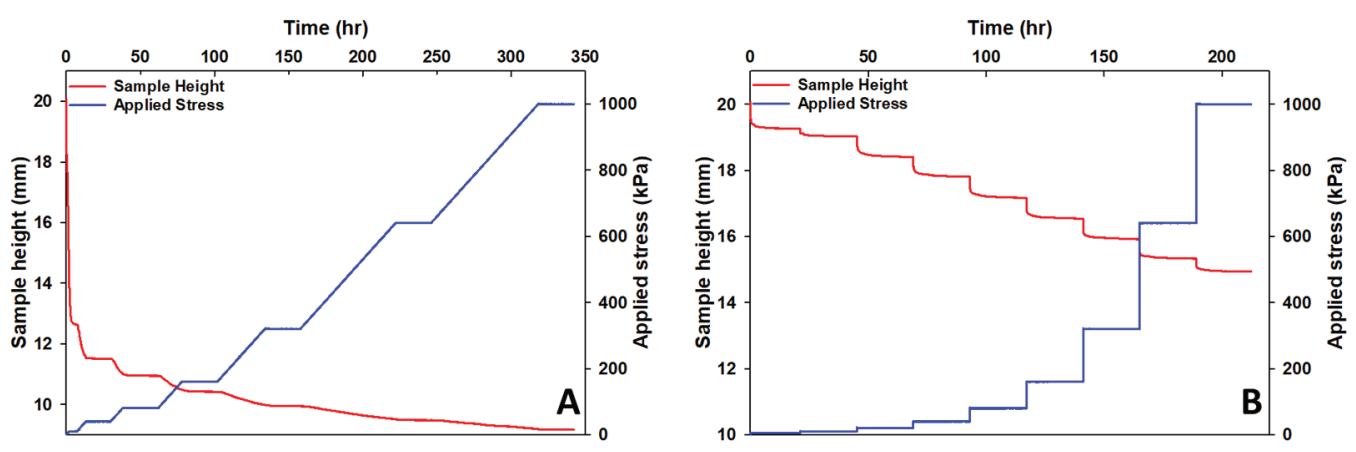

Figure 3 Applied stress and settlement results for (a) Raw slurry; (b) Ca-0.006-IV18 samples

Results of the changes on void ratio and hydraulic conductivity for both the untreated and polymer-treated samples are presented in Figure 4. The void ratio data of the polymer-treated sample are higher than that of raw slurry in all the applied loads with a different slope in each cycle. Similar to the previous studies on the impacts of polymer treatment, the polymer-treated materials resulted in the different normal consolidation 
lines (NCLs) compared to the untreated tailings, which is mostly related to its water content. Data are shown with respect to the average void ratio or vertical stress relevant to the loading increment for which they are calculated. The void ratio data showed a greater reduction at first. Based on the recorded data, the initial void ratio of raw slurry at $20 \mathrm{kPa}$ was 0.78 while the polymer-treated sample had the void ratio of 0.86 . Then, by applying the higher loads, the raw sample with a faster settling and releasing of its contained water compacted with lower void ratios, but the polymer-treated sample recorded higher void ratio due to having higher porosity generated among the aggregates.
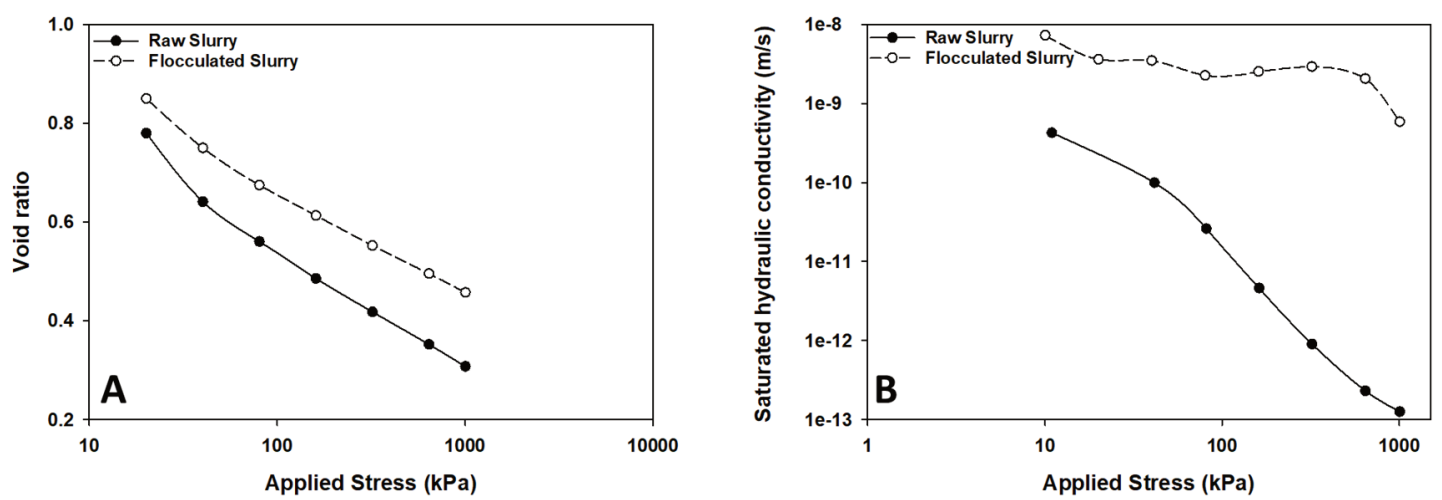

Figure 4 (a) Void ratio and (b) hydraulic conductivity over applied stress for both the raw and flocculated slurries

Polymer-treated material is seen to exhibit a higher hydraulic conductivity across the range of vertical stresses. Hydraulic conductivity $(\mathrm{k})$ can be calculated via the data from the consolidation test by multiplying the $\mathrm{Cv}\left(\mathrm{m}^{2} / \mathrm{s}\right)$ by the volume rate of compressibility $\mathrm{Mv}(1 / \mathrm{Pa})$ and unit weight of water $\left(\mathrm{kN} / \mathrm{m}^{3}\right)$ which is a reliable method for calculating the hydraulic conductivity value. The average amount of hydraulic conductivity ( $\mathrm{k}$ ) is mentioned in Table 2, plus the average consolidation coefficient (Cv) and coefficient of volume compressibility (Mv). There are many methods to determine the coefficient of consolidation (Cv), such as the Casagrande logarithm of time fitting method, the Taylor square root of time fitting method, and successive approximations method. In this research, the $\mathrm{Cv}$ values were determined using the most widely used Casagrande logarithmic time fitting method. In this method, the determination of the coefficient of consolidation normally requires that compression readings be carried out for at least 24 hours so that the slope of the compression curve attributed to the secondary compression of the soil can accurately be evaluated on a curve of compression versus logarithm of time. In Equation 1, $\mathrm{H}$ is the height of the sample and $t_{50}$ is read graphically as the time required for $50 \%$ consolidation (Shukla et al. 2009).

$$
C_{v}=\frac{0.197 H^{2}}{t_{50}}
$$

Table 2 Calculated average consolidation parameters and hydraulic conductivity

\begin{tabular}{llll}
\hline Sample & $\mathrm{C}_{\mathrm{v}}\left(\mathrm{cm}^{2} / \mathrm{s}\right)$ & $\mathbf{M}_{\mathrm{v}}(\mathbf{1} / \mathbf{k P a})$ & $\mathrm{K}(\mathrm{m} / \mathrm{s})$ \\
\hline Raw slurry & $2.72 \mathrm{e}-5$ & $1.31 \mathrm{e}-3$ & $3.48 \mathrm{e}-11$ \\
Polymer-treated slurry & 0.0062 & $1.01 \mathrm{e}-3$ & $6.15 \mathrm{e}-9$ \\
\hline
\end{tabular}

Toward determination of the ability of the materials to remove water from their porous media by changing the water content with suction, the water retention curve (WRC) test was conducted, and all calculated and driven parameters are reported in Table 3. Water retention curves were employed to evaluate the air entry values (AEVs) for each sample and to characterise their properties at a range of suctions by changing the soil wetness. The amount of water remaining in the materials at equilibrium is a function of properties of sizes and volumes of the water-filled pores, and so it is a function of the matric suction. This function is usually quantified experimentally, and it is represented graphically by a curve known as the soil-moisture retention curve, or the soil-moisture characteristic. Several empirical models predict the relationship between a porous 
materials or specific soil and unsaturated soil properties, such as shear strength and hydraulic conductivity through WRC data. Here, van Genuchten empirical models were applied, respectively, as the best fit on the experimental data. The water holding capacity of the materials was analysed in terms of (Assouline \& Dani 2014; de Oliveira et al. 2015):

$$
\Psi_{F C}=\frac{1}{\alpha}\left(\frac{n-1}{n}\right)^{\frac{(1-2 n)}{n}}
$$

Subsequently, the volumetric water contents were calculated based on the van Genuchten model (Assouline \& Dani 2014):

$$
\theta_{(\Psi)}=\theta_{r}+\frac{\theta_{S}-\theta_{r}}{\left[1+\left(\alpha|\Psi|^{n}\right)\right]^{1-1 / n}}
$$

where:

$$
\begin{aligned}
& \theta_{(\Psi)}=\text { water content }\left(L^{3} L^{-3}\right) . \\
& |\Psi|=\text { suction pressure }(L) . \\
& \theta_{s} \quad=\text { saturated water content }\left(L^{3} L^{-3}\right) . \\
& \theta_{r} \quad=\text { residual water content }\left(L^{3} L^{-3}\right) . \\
& \alpha \quad=\text { inverse of the air entry suction (1/L). } \\
& n \quad=\text { measure of the pore size distribution (Hilton et al. 2019). }
\end{aligned}
$$

Table 3 Soli-water characteristics data of both raw slurry and polymer amended tailings samples

\begin{tabular}{lllllllll}
\hline Sample & $\boldsymbol{\alpha}$ & $\mathbf{n}$ & $\boldsymbol{\theta} \mathbf{s}$ & $\boldsymbol{\theta}_{\mathbf{r}}$ & $\boldsymbol{\theta}_{\mathrm{FC}}$ & $\boldsymbol{\theta}_{\mathrm{WP}}$ & Macropore volume & Mesopore volume \\
\hline Raw slurry & 0.099 & 1.083 & 0.52 & 0 & 0.42 & 0.31 & 0.08 & 0.09 \\
Polymer-treated slurry & 0.071 & 1.054 & 0.57 & 0 & 0.47 & 0.36 & 0.1 & 0.11 \\
\hline
\end{tabular}

FC: field capacity; WP: wilting point; $\alpha$ : inverse of the air entry suction; $n$ : measure of the pore size distribution

The recorded data showed the polymer-treated sample drained almost $40 \%$ more free water compared to the untreated slurry at the start of the test just before $100 \mathrm{hPa}$ matric suction during the gravitational drainage, which is due to having higher porosity and hydraulic conductivity. In fact, drainability refers to the ability of a soil to get rid of excess water, or water in macropores, through downward movement by gravity. Here, the raw tailings have a lot of micropores that initially hold the water, but after the polymer treatment and converting to the macropores, the drainage surpassed and more water drained readily (Rai et al. 2017). Indeed, the addition of polymer to dewater the raw slurry altered the physical characteristics of the materials by producing different patterns for changing the volumetric water content over increasing the matric suction. These changes include (i) creating larger macropore areas to drain more water easily, (ii) changing the field capacity and permanent wilting points of the raw tailing in favour of having greater holding capacity, and (iii) improving the residual water content to prevent strong wilting of the materials which cause the preferential flow. These modifications, plus the larger particle's sizes, are linked with the hydraulic conductivity and provide conditions to move the water through the structure of the tailings differently in favour of rehabilitation purposes potentially for the long-term processes.

\section{Conclusion}

A comprehensive investigation was performed for finding and analysing the geotechnical properties and hydromechanical characteristics of polymer-treated tailings and compared it with the raw sample. The final outcomes can be concluded as follows.

- To possess both the highest water recovery with the lowest turbidity, and to prevent weak aggregation, high MW polyacrylamide/polyacrylate (IV24) was found to be more practical in 
flocculation of high salinity of $\mathrm{NaCl}$ salted slurries. Similar desirable flocculation performance was obtained on $\mathrm{CaCl}_{2}$ salted slurry at low concentration in presence of the unique molecular architecture flocculant (IV18).

- High MW polyacrylamide/polyacrylate (IV24) showed a contrasting effect on zeta potential by increasing the salinity of $\mathrm{NaCl}$ compared to $\mathrm{CaCl}_{2}$. This behaviour was attributed to the reversible or irreversible entanglements of the polymer long chains in presence of cations in which the $\mathrm{Na}+$ facilitated the coiling of the chains, while the $\mathrm{Ca} 2+$ ions protected the active sites and reduced the intermolecular bonding.

- Faster settling rate of the raw sample resulted in lower void ratio which showed a greater compressibility, while the polymer addition modified the structure of the material and produced a type of texture that distributed the applied stress through the porous media and controlled it to preserve its higher void ratio and consolidation rate.

- Comparison of the water retention characteristics of the materials before and after polymer treatment showed the capability of the polymer treatment in higher drainage of the free water. The polymer-treated sample represented greater water holding capacity, which is supporting evidence for relocating the normal consolidation line, which is a critical factor to assess the stability of a tailings beach by introducing higher void ratio and hydraulic conductivity with greater rate of consolidation.

\section{References}

Arinaitwe, E \& Pawlik, M 2013, 'A role of flocculant chain flexibility in flocculation of fine quartz. Part I. Intrinsic viscosities of polyacrylamide-based flocculants', International Journal of Mineral Processing, vol. 124, pp. 50-57, https://doi.org/10.1016/j.minpro.2013.01.006

Assouline, S \& O, Dani 2014, 'The concept of field capacity revisited: defining intrinsic static and dynamic criteria for soil internal drainage dynamics', Water Resources Research, vol. 50, no. 6, pp. 4787-4802, https://doi.org/10.1002/2014WR015475

Costine, A, Benn, F, Fawell, P, Edraki, M, Baumgartl, T \& Bellwood, J 2018a, 'Understanding factors affecting the stability of inline polymer-amended tailings', in RJ Jewell \& AB Fourie (eds), Paste 2018: Proceedings of the 21st International Seminar on Paste and Thickened Tailings, Australian Centre for Geomechanics, Perth, pp. 103-116, https://doi.org/10.36487/ACG_rep/ 1805_08_Costine

Costine, A, Cox, J, Travaglini, S, Lubansky, A, Fawell, P \& Misslitz, H 2018b, 'Variations in the molecular weight response of anionic polyacrylamides under different flocculation conditions', Chemical Engineering Science, vol. 176, pp. 127-138, https://doi.org/10.1016/j.ces.2017.10.031

Costine, A, Fawell, P, Chryss, A, Dahl, S \& Bellwood, J 2020, 'Development of test procedures based on chaotic advection for assessing polymer performance in high-solids tailings applications', Processes, vol. 8, no. 6, https://doi.org/10.3390/pr8060731

Costine, A, Lester, DR, Fawell, P \& Chryss, A 2014, 'Shear isn't mixing: how to build larger aggregates using chaotic advection for accelerated dewatering', in R Jewell, AB Fourie, PS Wells, D van Zyl (eds), Paste 2014: Proceedings of the 17th International Seminar on Paste and Thickened Tailings, InfoMine, Vancouver Inc., p. 644.

de Oliveira, RA, Ramos, MM \& de Aquino, LA 2015, 'Irrigation management', Sugarcane: Agricultural Production, Bioenergy and Ethanol, Academic Press, Cambridge, https://doi.org/10.1016/B978-0-12-802239-9.00008-6

Du, J, Morris, G, Pushkarova, RA \& Smart, R St C, 2010, 'Effect of surface structure of kaolinite on aggregation, settling rate, and bed density', Langmuir, vol. 26, pp. 13227-13235, https://doi.org/10.1021/la100088n

Fawell, PD, Costine, AD \& Grabsch, AF 2015, 'Why small-scale testing of reagents goes wrong', in R Jewell \& AB Fourie (eds), Paste 2015: Proceedings of the 18th International Seminar on Paste and Thickened Tailings, Australian Centre for Geomechanics, Perth, pp. 153-165, https://doi.org/10.36487/ACG_rep/1504_10_Fawell

Ghirian, A \& Fall, M 2013, 'Coupled thermo-hydro-mechanical-chemical behaviour of cemented paste backfill in column experiments. Part I: Physical, hydraulic and thermal processes and characteristics', Engineering Geology, vol. 164, pp. 195-207, https://doi.org/10.1016/j.enggeo.2013.01.015

Hilton, M, Shaygan, M, McIntyre, N, Baumgartl, T \& Edraki, M 2019, 'The effect of weathering on salt release from coal mine spoils', Minerals, vol. 9, no. 12, https://doi.org/10.3390/min9120760

Islam, S, Williams, DJ, Llano-Serna, M \& Zhang, C 2020, 'Settling, consolidation and shear strength behaviour of coal tailings slurry', International Journal of Mining Science and Technology, vol. 30, issue 60, pp. 849-857, https://doi.org/10.1016/ j.ijmst.2020.03.013

Jcu, R 2004, The Geotechnical Characterisation and Stability Analysis of BHP Billiton's Cannington Mine Paste Fill, PhD thesis, James Cook University, Townsville.

Jeeravipoolvarn, S 2010, Geotechnical Behavior of In-Line Thickened Oil Sands Tailings, PhD thesis, Univeristy of Alberta, Edmonton. 
Pearse, MJ 2003, 'Historical use and future development of chemicals for solid - liquid separation in the mineral processing industry', Minerals Engineering, vol. 16, issue 2, pp. 103-108, https://doi.org/10.1016/S0892-6875(02)00288-1

Pinheiro, M, Sobkowicz, J, Boswell, J \& Wells, S 2012, 'Modelling of the deposition profile of in-line flocculated mature fine tailings in beach cells', Proceedings of Geo-Manitoba 2012: 65th Canadian Geotechnical Conference, Canadian Geotechnical Society.

Rai, RK, Singh, VP \& Upadhyay, A 2017, 'Chapter 17 - soil analysis', Planning and Evaluation of Irrigation Projects: Methods and Implementation, in RK Rai, VP Singh \& A Upadhyay (eds), Academic Press, pp. 505-523, https://doi.org/10.1016/B978-0-12811748-4.00017-0

Ramos, J, Leiva, WH, Castillo, C, Ihle, CF, Fawell, PD \& Jeldres, RI 2020, 'Seawater flocculation of clay-based mining tailings: impact of calcium and magnesium precipitation', Minerals Engineering, vol. 154, https://doi.org/10.1016/j.mineng.2020.106417

Reid, C, Bécaert, V, Aubertin, M, Rosenbaum, RK \& Deschênes, L 2009, 'Life cycle assessment of mine tailings management in Canada', Journal of Cleaner Production, vol. 17, issue 4, pp. 471-479, https://doi.org/10.1016/j.jclepro.2008.08.014

Reid, D \& Fourie, AB 2016, 'Laboratory assessment of the effects of polymer treatment on geotechnical properties of low-plasticity soil slurry', Canadian Geotechnical Journal, pp. 1718-1730.

Sabah, E \& Cengiz, I 2004, 'An evaluation procedure for flocculation of coal preparation plant tailings', Water Research, vol. 38, issue 6, pp. 1542-1549, https://doi.org/10.1016/j.watres.2003.12.017

Shaygan, M, Reading, LP \& Baumgartl, T 2017, 'Effect of physical amendments on salt leaching characteristics for reclamation', Geoderma, vol. 292, pp. 96-110, https://doi.org/10.1016/j.geoderma.2017.01.007

Shukla, SK, Sivakugan, N \& Das, BM 2009, 'Methods for determination of the coefficient of consolidation and field observations of time rate of settlement - an overview', Internatonal Journal Geotechnical Engineering, vol. 3, issue 1, pp. 89-108, https://doi.org/10.3328/IJGE.2009.03.01.89-108

Tombácz, E \& Szekeres, M 2004, 'Colloidal behavior of aqueous montmorillonite suspensions: the specific role of pH in the presence of indifferent electrolytes', Applied Clay Science, vol. 27, issues 1-2, pp. 75-94, https://doi.org/10.1016/j.clay.2004.01.001

Torres Lopez, C, Catling, M, Bellwood, J \& Boxill, L 2019, 'The effect of preconditioning of tailings prior to inline flocculation and deposition', in AJC Paterson, AB Fourie \& D Reid (eds), Paste 2019: Proceedings of the 22nd International Conference on Paste, Thickened and Filtered Tailings, Australian Centre for Geomechanics, Perth, pp. 285-293, https://doi.org/10.36487/ ACG_rep/1910_19_Torres_Lopez

Watson, P, Farinato, R, Fenderson, T, Hurd, M, Macy, P \& Mahmoudkhani, A 2011, 'Novel polymeric additives to improve oil sands tailings consolidation', paper presented at the SPE International Symposium on Oilfield Chemistry, The Woodlands, 11-13 April 2011, https://doi.org/10.2118/141398-MS

Wells, P, Revington, A \& Omotoso, O 2011, 'Mature fine tailings drying - technology update', in R Jewell \& AB Fourie (eds), Paste 2011: Proceedings of the 14th International Seminar on Paste and Thickened Tailings, Australian Centre for Geomechanics, Perth, pp. 155-166, https://doi.org/10.36487/ACG_rep/1104_15_Wells

Williams, PA (ed.) 2007, Handbook of Industrial Water Soluble Polymers, Blackwell Publishing Ltd, Hoboken, https://doi.org/10.1002/9780470988701

Yang, X \& You, X 2013, 'Estimating parameters of van genuchten model for soil water retention curve by intelligent algorithms', Applied Mathematics \& Information Sciences, vol. 7, no. 5, pp. 1977-1983, https://doi.org/10.12785/amis/070537

Yu, H 2015, Geotechnical Properties and Flow Behaviour of Coal Refuse Under Static and Impact Loading, Case Western Reserve University, Cleveland. 
